\title{
Enhancing Thermo-Mechanical Properties of Epoxy Composites Using Fumed Silica with Different Surface Treatment
}

\author{
Kyung-Min Kim ${ }^{1}{ }^{1}$, Hoon Kim $^{2}{ }^{\circledR}$ and Hyun-Joong Kim ${ }^{1,2, *}$ \\ 1 Laboratory of Adhesion \& Bio-Composites, Department of Agriculture, Forestry and Bioresources, \\ Seoul National University, Seoul 08826, Korea; min913@snu.ac.kr \\ 2 Research Institute of Agriculture and Life Sciences, College of Agriculture and Life Sciences, \\ Seoul National University, Seoul 08826, Korea; c12o2cl4@snu.ac.kr \\ * Correspondence: hjokim@snu.ac.kr; Tel.: +82-28804784; Fax: +82-28732318
}

Citation: Kim, K.-M.; Kim, H.; Kim, H.-J. Enhancing Thermo-Mechanical Properties of Epoxy Composites Using Fumed Silica with Different Surface Treatment. Polymers 2021, 13, 2691. https://doi.org/10.3390/ polym13162691

Academic Editors: Chih-Wei Chiu, Chih-Chia Cheng and Jia-Wun Li

Received: 8 July 2021

Accepted: 8 August 2021

Published: 12 August 2021

Publisher's Note: MDPI stays neutra with regard to jurisdictional claims in published maps and institutional affiliations.

Copyright: (c) 2021 by the authors. Licensee MDPI, Basel, Switzerland. This article is an open access article distributed under the terms and conditions of the Creative Commons Attribution (CC BY) license (https:// creativecommons.org/licenses/by/ $4.0 /)$.

\begin{abstract}
The objectives of this study are to improve the thermal and mechanical properties of epoxy/fumed silica composite with different surface treatments of fumed silica. The addition of silica nanoparticles improved the thermal stability of the composite and slowed down the pyrolysis process. The crosslinking density and $\mathrm{T}_{\mathrm{g}}$ of the epoxy/fumed silica composites increased because of the interfacial interaction between the PDMS-treated fumed silica particles and the epoxy matrix. The flexural strength of the epoxy nanocomposite was very high even at a low silica content because of the strong interactions between the PDMS-treated fillers and the epoxy matrix. These strong interfacial interactions originate from the attractive forces between the polymer and the filler. Therefore, the polymer nanocomposite containing the PDMS-treated fumed silica is shown to be sufficiently commercially promising.
\end{abstract}

Keywords: silica nanoparticle; epoxy/fumed silica composites; thermal stability; thermo-mechanical properties

\section{Introduction}

In engineering structures, components such as factory piping are exposed to high temperatures; hence, these materials should exhibit high durability, chemical resistance, and thermal stability. As an important requirement for industries, design of high-strength materials with heat resistance has been prioritized [1]. Polymer-based composites are the most widely used materials for structural applications because of their easy processability and low costs. Polymer/inorganic filler composites have received considerable scientific and industrial attention over the past few decades because of their unique properties originating from the combined advantages of inorganic materials and polymers [2-5]. The dispersion degree of inorganic fillers and the interfacial interaction between the polymer matrix and fillers are important factors to be considered for the preparation of polymer/fumed silica composites. The interfacial cohesive forces of the filler and the polymer matrix have a direct effect on the interfacial stress transfer of the composite structure; therefore, they significantly affect the thermo-mechanical properties of the composite. The high surface-tovolume ratio of the nanomaterial increases the interfacial interaction between the nanofiller and the matrix. Various methods have been used to enhance the interfacial interaction, and numerous studies have been conducted to improve the chemical activity of the filler surface or increase the surface area [6-9]. Among the available polymer/fumed silica composites, polymer/silica composites have been studied extensively. In addition, there is a method of synthesizing silica filler in one-pot or blending method for manufacturing a polymer/silica composite material [10-12]. In order to improve the dispersibility of fillers in polymeric binders, Battistella, M. et al., conducted a study on the chemical surface treatment of silver alumina fillers. Shirono, H. et al., conducted a study on the length of alkyl chains introduced to the surface of silver fumed silica, and El-Fattah, M.A. et al., reported the results 
of a study on the effect of physical properties on filler size. With reference to these prior studies, a polymer/fumed silica composite was prepared using nano-sized chemically surface-treated fumed silica as a filler, and dispersibility was compared. Because, the interactions between the polymer precursor and the interface can be enhanced through chemical surface treatment of the silica surface. Fumed silica is hydrophilic owing to the presence of silanol group ( $\mathrm{Si}-\mathrm{OH})$, and it has a low dispersibility owing to particle aggregation; these are major disadvantages [13-15]. The hydroxyl groups present on the silica surface can be transformed into organic compounds or polymers through chemical modification. The physical properties, i.e., dispersibility and interfacial interactions, can be improved using fumed silica particles with polydimethylsiloxane (PDMS) surface treatment [16,17].

The binders used in most polymer composites are composed of a thermosetting resin and epoxy. Epoxy resins are widely used in various industrial applications, such as paints, coatings, composite materials, 3D printing, and adhesives, because of their excellent mechanical properties, heat resistance, insulation, and adhesive strength. Moreover, it is possible to control their curing rate by adding various curing agents. However, low conductivities and high coefficients of thermal expansion are the major disadvantages of epoxy resins. Further, this material has a weak external-impact withstanding capability because of its high crosslinking density due to the formation of a 3D network structure. Therefore, when an epoxy composite is used in combination with a material having a different coefficient of thermal expansion, such as a metal, peeling or cracking may occur because of their different thermal deformations. In recent times, many studies have been conducted to improve the fluidity and enhance the impact reinforcement effects of epoxy resins by introducing fumed silica particles [18-22]. These particles serve as inorganic fillers to produce epoxy nanocomposite materials. However, only a few studies on the comparison of thermal and mechanical properties of epoxy nanocomposites have been reported for their application in structures exposed to high temperatures.

In this study, fumed silica with different surface properties was physically dispersed in an epoxy resin, and then the viscosity of the resulting mixture was measured to confirm the dispersibility of fumed silica in epoxy resin. The curing behavior of the mixture was analyzed by differential scanning calorimetry (DSC). The thermal stability of the cured epoxy nanocomposite was confirmed through thermogravimetric analysis (TGA), and its glass transition temperature $\left(\mathrm{T}_{\mathrm{g}}\right)$ and crosslinking density were determined by dynamic mechanical analysis (DMA). Moreover, a bending test was performed using a universal testing machine to study the mechanical properties of the epoxy nanocomposite.

\section{Materials and Methods}

\subsection{Materials}

A bisphenol A-type epoxy resin (YD-115, E.E.W. 187 g/eq, KUKDO CHEMICAL CO., Seoul, Republic of Korea) containing diglycidyl ether of bisphenol A (DGEBA) with butyl glycidyl ether (BGE) was used. Butyl glycidyl ether (BGE) and polyether diamines (JEFFAMINE ${ }^{\circledR}$ D-230, A.H.E.W. 60 g/eq, HUNTSMAN Corporation, Salt Lake City, TX, USA ) were used as the curing agents. The molecular structures of the epoxy and polyether diamines are shown in Figure 1a.

Fumed silica (AEROSIL ${ }^{\circledR} 150$; surface area: $150 \pm 15 \mathrm{~m}^{2} / \mathrm{g}$ ) and PDMS-treated fumed silica (AEROSIL ${ }^{\circledR}$ R202; surface area: $100 \pm 20 \mathrm{~m}^{2} / \mathrm{g}$ ) were provided by Evonik Industries (Essen, Germany). 
(a)

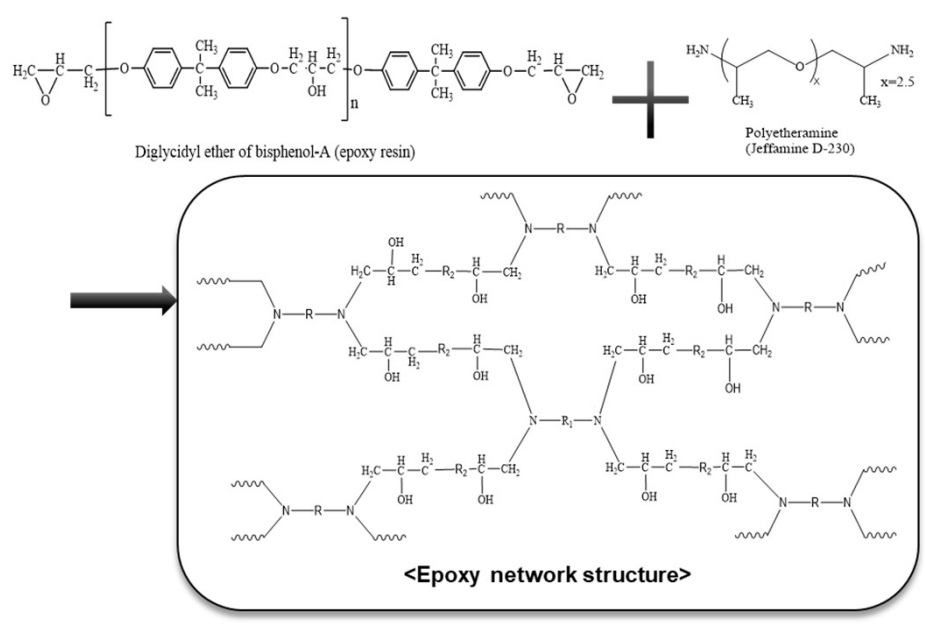

(b)

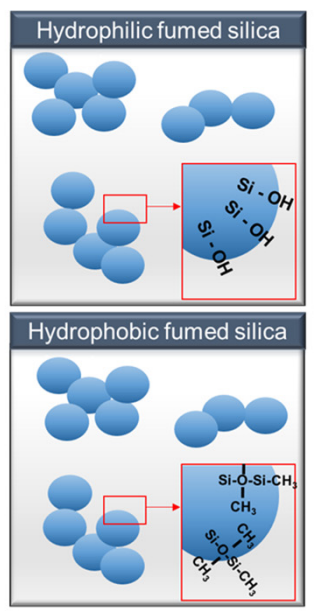

(c)

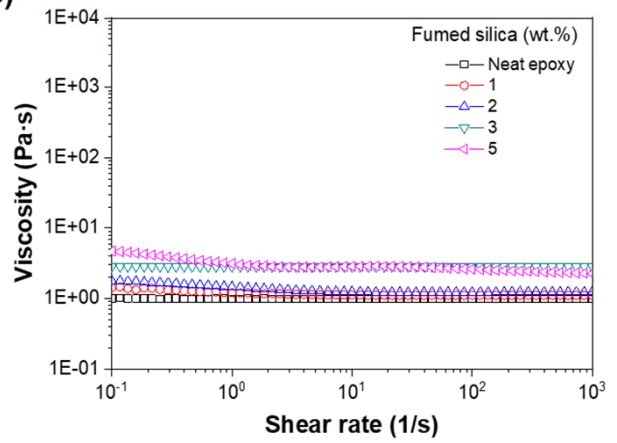

(d)

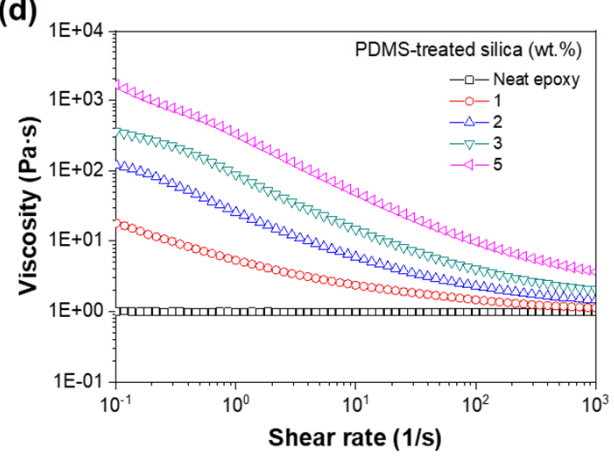

Figure 1. (a) Molecular structures of the epoxy resin and polyether diamine crosslinking agent and schematic of the molecular epoxy network structure. (b) Schematics of the hydrophilic fumed silica (Aerosil ${ }^{\circledR} 150$ ) and hydrophobic fumed silica (Aerosil ${ }^{\circledR}$ R202) structures. Steady shear viscosities of silica/epoxy resin as a function of filler fraction: (c) Hydrophilic fumed silica and (d) hydrophobic PDMS-treated silica.

\subsection{Preparation of Epoxy Fumed Silica Composites}

The epoxy/fumed silica composite was produced by uniformly dispersing fumed silica in an epoxy resin and then adding a curing agent to the mixture. The equivalent ratio, curing agent:epoxy, was fixed at 1:1.24 (Table 1).

Table 1. Formulation of epoxy/fumed silica composites.

\begin{tabular}{ccccc}
\hline \multirow{2}{*}{ Sample } & \multirow{2}{*}{ Epoxy Resin (g) } & \multirow{2}{*}{ Curing Agent (g) } & \multicolumn{2}{c}{ Filler } \\
\cline { 4 - 5 } & & & $\mathbf{( g )}$ & $\mathbf{( w t . \% )}$ \\
\hline Pure epoxy & & & 0.14 & 0 \\
Ep/F1 & \multirow{2}{*}{10} & & 0.29 & 1 \\
Ep/F2 & & 0.43 & 2 \\
Ep/F3 & & 0.74 & 5 \\
Ep/F5 & & & 5 \\
\hline
\end{tabular}

Curing agent:epoxy resin ratio $=1: 1.24$. Filler used-Silica nanoparticle (AEROSIL ${ }^{\circledR} 150$, AEROSIL $^{\circledR}$ R202).

First, fumed silica was dispersed in an appropriate amount of the epoxy resin at $2000 \mathrm{rpm}$ for $10 \mathrm{~min}$ by using a paste mixer (ARV-310, Thinky, Tokyo, Japan), followed by stirring at $23^{\circ} \mathrm{C}$ for $3 \mathrm{~min}$ and ultrasonication (VCX 750, Ultrasonic Processor, Sonic \& Materials, Newton, CT, USA). After cooling, a curing agent was added and the defoaming process was performed for $1 \mathrm{~min}$. Next, epoxy/fumed silica mixture with the curing agents 
was initially cured at $80^{\circ} \mathrm{C}$ in a Teflon sheet for $3 \mathrm{~h}$, and the solvent was evaporated, followed by post-curing at $150{ }^{\circ} \mathrm{C}$ for $2 \mathrm{~h}$ (Figure S1).

\subsection{Characterization and Measurements}

Fourier transform infrared (FTIR) spectroscopy was conducted between 4000 and $400 \mathrm{~cm}^{-1}$ using a BERTEX80 FTIR spectrometer (BRUKER, North Billerica, MA, USA) to identify the functional groups present in fumed silica. After the sample was dried at $160^{\circ} \mathrm{C}$ for $24 \mathrm{~h}$, a $\mathrm{KBr}$ pellet was prepared for the FTIR characterization. The number of scans was 32 , and the resolution was $4 \mathrm{~cm}^{-1}$. Field-emission scanning electron microscopy (FESEM; SUPRA 55VP, Carl Zeiss, Jena, Germany) was employed to analyze the structure of fumed silica (Figure S2). The morphology of the epoxy/fumed silica composites was also investigated by high-resolution transmission electron microscopy (TEM; JEM-2100F, JEOL Ltd., Tokyo, Japan). The specimens for TEM analysis were cut using an ultramicrotome (EM UC7, Wetzlar, Germany) fitted with a diamond knife, and the corresponding TEM images were obtained at an acceleration voltage of $200 \mathrm{kV}$.

The difference in the dispersibilities of the fumed silica that underwent different surface treatments was determined by measuring the viscosity of the untreated and the treated fumed silica and epoxy resin mixture at room temperature using a rheometer (MCR-302, Anton Paar, Ostfildem, Germany) equipped with parallel plates, each with a diameter of $25 \mathrm{~mm}$. Steady shear measurement was then performed at a shear rate range of 0.01 to $10^{3} \mathrm{~s}^{-1}$, and the results were analyzed to obtain the rheological properties of the fumed silica-epoxy resin mixture.

To examine the thermal stability of the composites, TGA of the epoxy/fumed silica composites was performed using a TGA 4000 system (Perkin Elmer, Waltham, MA, USA). The TGA measurements were conducted at a heating rate of $10{ }^{\circ} \mathrm{C} / \mathrm{min}$, over a temperature range of $30-800{ }^{\circ} \mathrm{C}$, under a constant nitrogen flow atmosphere. Specimens were measured only once for each content. The curing behavior of the epoxy/fumed silica and epoxy/PDMS-treated fumed silica was examined by DSC (Q200, TA Instruments, New Castle, DE, USA) at a heating rate of $10{ }^{\circ} \mathrm{C} / \mathrm{min}$ (from 30 to $30{ }^{\circ} \mathrm{C}$ ) under a nitrogen flow of $20 \mathrm{~mL} / \mathrm{min}$. Three specimens were measured.

The temperature dependences of the dynamic storage modulus $\left(\mathrm{G}^{\prime}\right)$ and $\tan \delta$ values of the epoxy/fumed silica composites were evaluated by DMA (Q800, TA instruments, New Castle, DE, USA) in the film-tension mode over a temperature range of $35-200{ }^{\circ} \mathrm{C}$, at a heating rate of $5{ }^{\circ} \mathrm{C} / \mathrm{min}$, strain rate of $0.1 \%$, and frequency of $1 \mathrm{~Hz}$. The dimensions of the specimens were $60 \mathrm{~mm} \times 12 \mathrm{~mm} \times 3 \mathrm{~mm}$. The flexural properties of the composites were determined using a three-point bend test. The epoxy/fumed silica composites were measured using a $10 \mathrm{kN}$ universal testing machine (Z010, Zwick, Ulm, Germany) at a crosshead speed of $0.1 \mathrm{~mm} / \mathrm{s}$. The flexural specimens had dimensions of $60 \mathrm{~mm} \times 12 \mathrm{~mm}$ $\times 3 \mathrm{~mm}$. The tests were performed at a temperature of $25 \pm 1{ }^{\circ} \mathrm{C}$ and humidity of $50 \pm 2 \%$ $\mathrm{RH}$, in accordance with the ASTM D790 standard methods.

\section{Results and Discussion}

\subsection{Characterization}

In this study, a DGEBA-type epoxy resin diluted in BGE was used as the epoxy resin, and polyether diamines were used as the crosslinkers. Figure 1a shows the schematic of the resulting epoxy network structure [23]. Fillers with different surface functional groups were selected for the experiment (Figure S2) [24].

As shown in Figure 1b, the fumed silica without surface treatment contains a silanol group ( $\mathrm{Si}-\mathrm{OH})$ as the functional group, whereas the PDMS-treated fumed silica has exposed methyl groups, as confirmed via FTIR analysis (Figure S3). The FTIR spectrum of the untreated fumed silica showed characteristic asymmetric stretching, symmetric stretching, and bending vibrations of the $\mathrm{Si}-\mathrm{O}-\mathrm{Si}$ band at 1103,804 , and $472 \mathrm{~cm}^{-1}$, respectively. The spectrum also showed absorption peaks at 3435 and $1631 \mathrm{~cm}^{-1}$, which could be assigned to the stretching and bending vibrations of the $\mathrm{OH}$ group on the silica surface. In the FTIR 
spectrum of the PDMS-treated fumed silica, additional peaks at 2960 (assigned to C-H stretching in $\left.\mathrm{CH}_{3}\right), 1262\left(\mathrm{CH}_{3}\right.$ symmetric bending in $\left.\mathrm{Si}-\mathrm{CH}_{3}\right)$, and $804 \mathrm{~cm}^{-1}\left(-\mathrm{CH}_{3}\right.$ rocking in $\mathrm{Si}-\mathrm{CH}_{3}$ ) were observed, which confirmed the existence of different functional groups in the PDMS-treated fumed silica $[15,23,25-27]$.

After sufficiently dispersing the fumed silica with different surface functional groups in the epoxy resin (YD-115) through mixing and ultrasonication, the steady shear viscosities of the mixtures with different silica contents were measured (Figure 1c,d). As shown in Figure 1c, the untreated silica suspensions exhibited Newtonian fluid behavior, whereas the viscosities of the epoxy/PDMS-treated silica mixtures showed a strong dependence on the silica content, as shown in Figure $1 \mathrm{~d}$. The viscosity of the mixtures decreased with increase in the shear rate. This characteristic, called the shear thinning behavior, is typical of non-Newtonian fluids. Shirono $\mathrm{H}$. et al., measured the viscosity of fumed silica by surface treatment with silanes with different alkyl chain lengths on the surface. Suspensions of untreated fumed silica and low chain length treated fumed silica showed Newtonian behavior. However, strong shear thinning behavior was observed in the surfacemodified fumed silica with longer alkyl groups. Additionally, Mai, V.D. et al., showed a shear thinning behavior in which the viscosity of the epoxy resin $/$ nano- $\mathrm{Al}_{2} \mathrm{O}_{3}$ composite material decreased as the shear rate increased [14,28]. Compared with the results of published literature, it shows similar research results in which the behavior of Newtonian and non-Newtonian fluids according to the different surface treatment of the filler. The shear thinning behavior of the mixtures can be attributed to the redistribution of fillers and their directions.

\subsection{Curing Behavior}

The curing reaction of the epoxy composites was investigated by DSC. Figure $2 \mathrm{a}, \mathrm{b}$ show the DSC thermograms of the cured epoxy and its composites for the untreated and the different PDMS-treated fumed silica contents. Evidently, the peak maximum temperature, defined as $T_{p}$, decreased with increase in the epoxy/fumed silica composite filler content. The $\mathrm{T}_{\mathrm{p}}$ decreased from 132.5 to $129^{\circ} \mathrm{C}$ as the PDMS-treated fumed silica content was increased from 1 to $5 \mathrm{wt}$ \%, respectively, as shown in Figure S4. The peak maximum is shifted toward the lowest temperatures for the composites with $5 \mathrm{wt} . \%$ of untreated fumed silica and PDMS-treated fumed silica. This indicates that fumed silica has a catalytic effect on the curing reaction of the epoxy composite (Figure 2c). Jiang W. et al., Jin, F.L. et al., and Omrani, A. et al. reported similar observations of catalytic effect using the epoxy/alumina nanoparticle composites $[27,29,30]$. This means that high weight percent of nanoparticle filler has a converse effect on the polymer network formation. It could be described by topological restrictions produced during the epoxy network evolution. This only refers to the behavior that has an adverse effect on network formation during the curing process of the epoxy/nanocomposite. These results also confirm that the polymer chains are constrained by the interface-particle interactions [24,31-33]. 
(a)

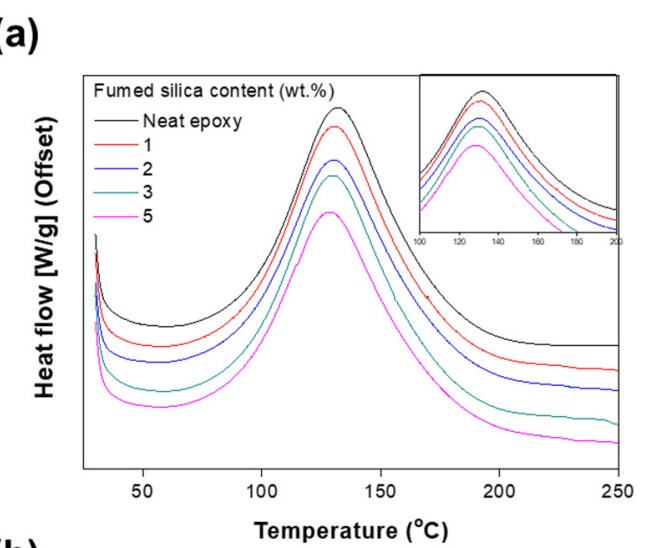

(b)
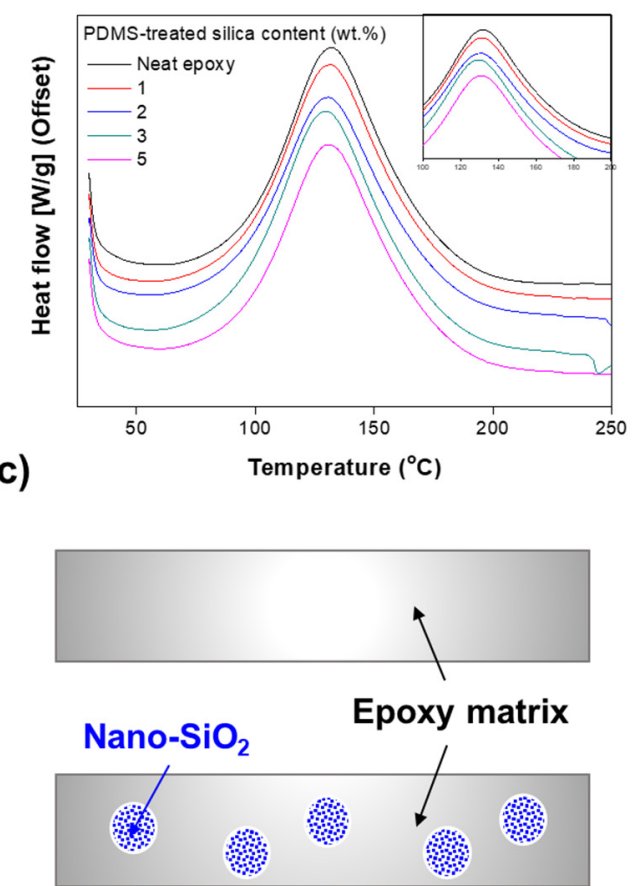

$\rightarrow$ "Catalytic effect"

Figure 2. DSC curves of epoxy nanocomposites with (a) fumed silica and (b) PDMS-treated fumed silica. (c) Schematic of the catalytic effect.

\subsection{Morphology}

The morphological characteristics of the epoxy/fumed silica composites with $3 \mathrm{wt} . \%$ fumed silica were analyzed by TEM. Figure $3 a, b$ show the TEM images of the untreated fumed silica, and Figure 3c,d show those of the surface-treated fumed silica. Evidently, the specific surface areas of the untreated and the treated fumed silica were similar. As shown Figure 3a,c, both fumed silica and PDMS-treated silica particles are uniformly dispersed. However, the sizes of the untreated fumed silica particles observed in Figure $3 \mathrm{~b}$ are larger than those of the treated fumed silica particles in Figure 3d. This is because the silanol $(\mathrm{Si}-\mathrm{OH})$ group on the surface of the untreated fumed silica particles allows moisture absorption [6,31-33]. 

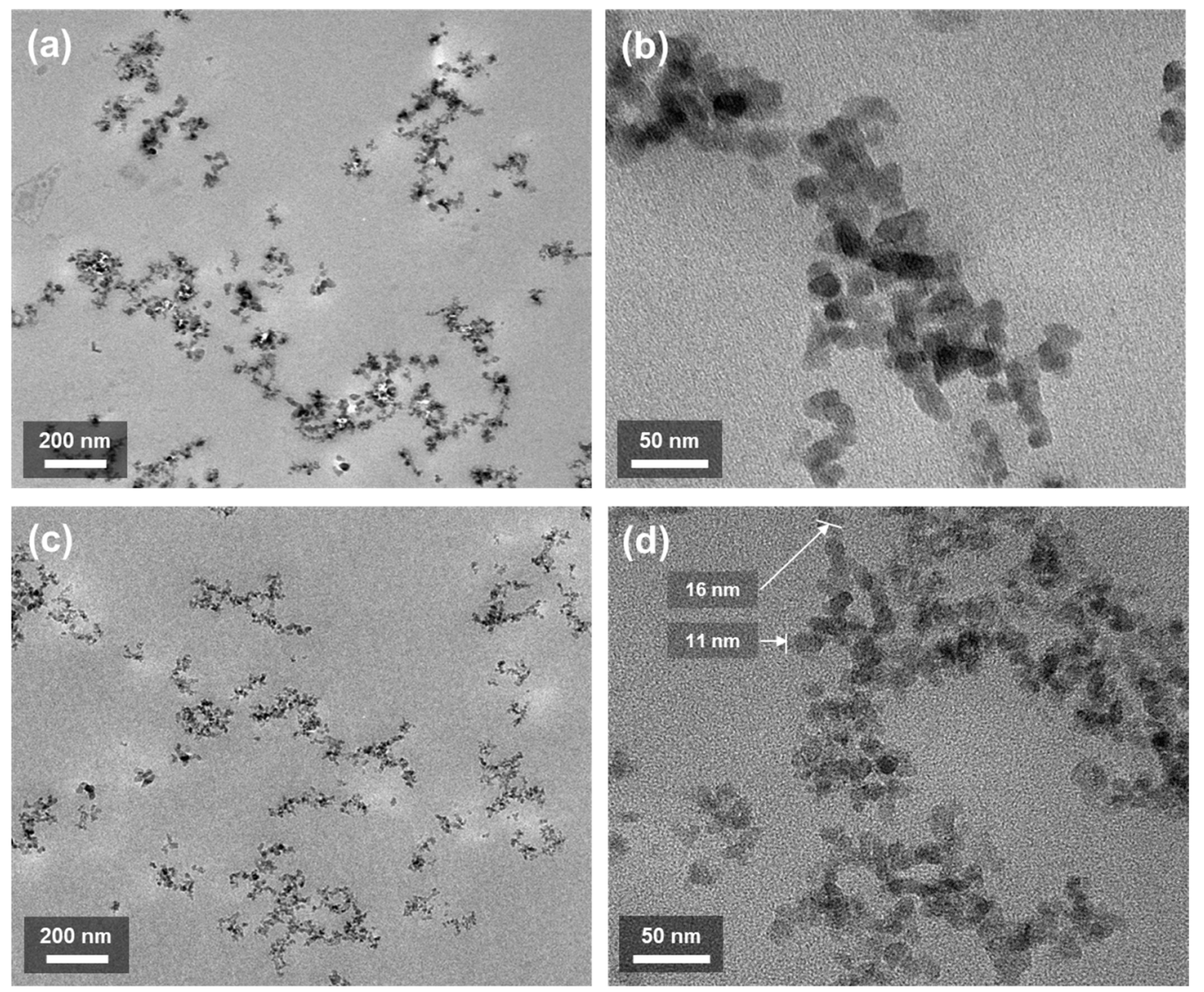

Figure 3. TEM images of the epoxy/fumed silica composite with $3 w t . \%(\mathbf{a}, \mathbf{b})$ fumed silica and (c,d) PDMS-treated silica.

\subsection{Thermal Stability}

To determine the thermal stability, TGA of the epoxy/fumed silica composite was performed. The TGA curves of the pure epoxy and epoxy/fumed silica composites showed similar thermal degradation tendencies as evident from Figure $4 a, b$. In general, the maximum mass loss occurred at approximately $300-600{ }^{\circ} \mathrm{C}$. The addition of silica nanoparticles improved the thermal stability of the composite and delayed the thermal decomposition process. At $800{ }^{\circ} \mathrm{C}$, the amount of char increases with increase in the fumed silica content. However, the char yield is not $0 \%$ for the pure epoxy at $800{ }^{\circ} \mathrm{C}$. This may be attributed to the carbonization of the epoxy matrix and the presence of unreacted substances $[34,35]$. The difference between the char yields of the pure epoxy and the epoxy/fumed silica composites, produced at $800^{\circ} \mathrm{C}$, was defined as "Gap" to assess the rate of formation of char with increase in the filler content.

$$
\mathrm{Gap}=\mathrm{W}_{\mathrm{f}}-\mathrm{W}_{0}
$$

where $\mathrm{W}_{\mathrm{f}}$ is the char yield (\%) of epoxy/fumed silica composites, and $\mathrm{W}_{0}$ is the char yield $(\%)$ of pure epoxy. The untreated fumed silica rapidly formed char upon heating to high temperatures. Owing to the good dispersibility of PDMS-treated fumed silica, only a small amount of char is formed in the beginning; however, there is a steep increase in the char formation when the silica content is increased to $5 \mathrm{wt} . \%$.

$\mathrm{Td}_{5}$ was defined as the temperature at which the mass percentage of the epoxy/fumed silica composite decreased by approximately 5\% (Figure S5a,b). Figure S5d shows the TGA results of the pure fumed silica filler. The mass of the untreated fumed silica was reduced by approximately $2 \%$. The mass of the epoxy/surface-treated fumed silica composite decreased rapidly above $300{ }^{\circ} \mathrm{C}$, and a char yield of approximately $88 \%$ was obtained at $800{ }^{\circ} \mathrm{C}$. In the case of the epoxy composite with PDMS-treated fumed silica, the $\mathrm{Td}_{5}$ should 
be actually low owing to the decomposition of organic matter on the surface. However, there were no significant differences in the $\mathrm{Td}_{5}$ values of the epoxy/surface-treated fumed silica composites. This suggests that the PDMS-treated fumed silica undergoes uniform dispersion in the epoxy resin to form a complex.

(a)

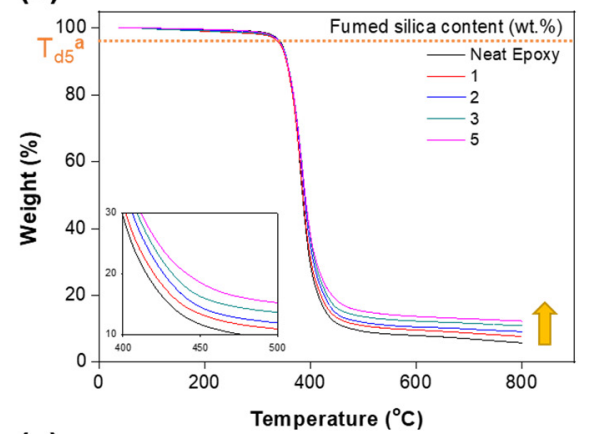

(c)

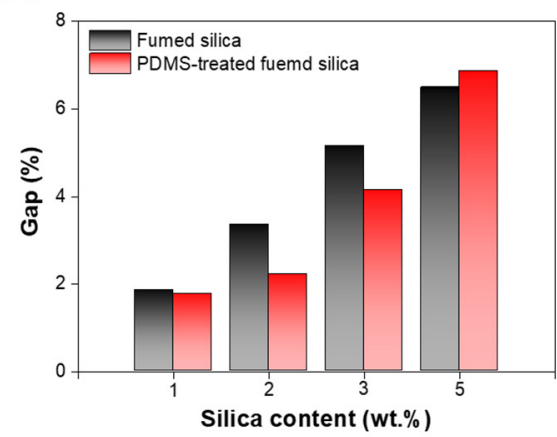

(b)

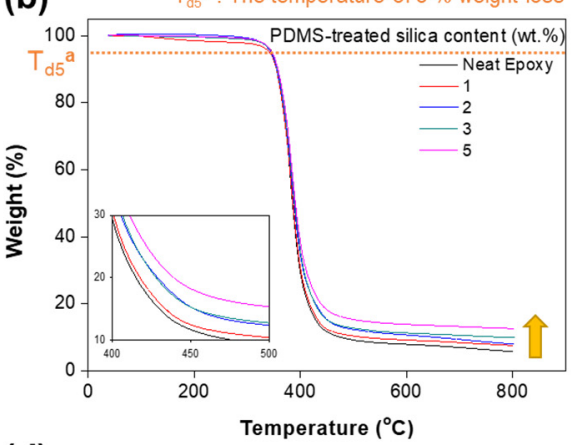

(d)

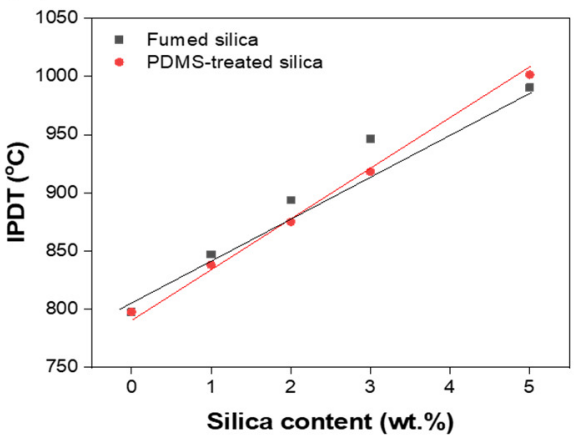

Figure 4. Thermograms of epoxy composites with (a) fumed silica and (b) PDMS-treated fumed silica. (c) Gap of char weight percent at $800{ }^{\circ} \mathrm{C}$. (d) Integral procedural decomposition temperature (IPDT) of the epoxy/fumed silica composites.

The integral procedural decomposition temperature (IPDT), proposed by Doyle, is related to the volatile fraction of polymers and can be utilized to estimate the overall intrinsic thermal stability of polymers during decomposition. In this study, the IPDT was calculated from the TGA curve using the following equations [36-39]:

$$
\begin{gathered}
\mathrm{IPDT}=\mathrm{A}^{*} \mathrm{~K}^{*}\left(\mathrm{~T}_{\mathrm{f}}-\mathrm{T}_{\mathrm{i}}\right)+\mathrm{T}_{\mathrm{i}}, \\
\mathrm{A}^{*}=(\mathrm{S} 1+\mathrm{S} 2) /(\mathrm{S} 1+\mathrm{S} 2+\mathrm{S} 3), \\
\mathrm{K}^{*}=(\mathrm{S} 1+\mathrm{S} 2) / \mathrm{S} 1,
\end{gathered}
$$

where $\mathrm{A}^{*}$ is the area ratio of the total experimental curve divided by the total TGA thermogram, $\mathrm{K}^{*}$ is the modulus, $\mathrm{T}_{\mathrm{i}}$ is the initial experimental temperature $\left(35^{\circ} \mathrm{C}\right)$, and $\mathrm{T}_{\mathrm{f}}$ is the final experimental temperature $\left(800^{\circ} \mathrm{C}\right)$. For the analysis, the TGA plot was divided into three regions represented by S1, S2 and S3, as shown in Figure S5c. The linear line was drawn from point IPDT at $0 \mathrm{wt} . \%$ to point IPDT at $5 \mathrm{wt} . \%$ in Figure $4 \mathrm{~d}$.

Jin, F.L. et al. and Chiang, C.L. et al. showed that nano inorganic particle improve the thermal stability of pure epoxy. Liu, Y.L. et al. reported epoxy-silica hybrid composites have an increase in IPDT with increasing silica content. It means that silica particles contribute to the level-up of IPDT while delaying the thermal decomposition rate of the organic part of the organic-inorganic hybrid composite [26,36,39]. The IPDTs of untreated and treated fumed silica-epoxy composites increased with increase in the silica content. At low filler contents, the difference in the IPDTs of the untreated and treated silica/epoxy composites was negligible. At a high silica content ( $5 \mathrm{wt} . \%)$, the IPDT of the PDMStreated silica/epoxy composite was approximately $10{ }^{\circ} \mathrm{C}$ higher than that of the untreated 
silica/epoxy composite. Compared with the published literature, the thermal stability of the silica weight fraction of the epoxy/thin silica nanocomposite has similar observations. In contrast to the influence of the silica weight fraction, the difference value of IPDT on the surface treatment of the filler is low. However, It indicated that the PDMS-treated silica/epoxy composite shows better thermal stability (Figure S5a,b).

\subsection{Thermo-Mechanical Properties}

The effect of silica nanoparticles with different surface functional groups on the viscoelastic properties of the crosslinked polymers was analyzed using DMA (Figure 5). The storage modulus and $\tan \delta$ of the pure epoxy and composites showed temperature dependence (Figure $5 \mathrm{a}, \mathrm{b}$ ). Figure $5 \mathrm{a}, \mathrm{b}$ show that the $\mathrm{T}_{\mathrm{g}}$ of the epoxy composite containing silica nanoparticles is higher than that of the pure epoxy resin by approximately $5{ }^{\circ} \mathrm{C}$ [40-44]. Figure 5a shows that the storage modulus at the initial temperature increased as the untreated fumed silica filler content increased. However, the storage modulus at the initial temperature of the PDMS-treated fumed silica/epoxy composite was not dependent on the filler content. The results for epoxy/fumed silica composite confirmed that the storage modulus in the rubbery region increased as the filler content increased (Figure S6a,b). The crosslinking density of the epoxy/fumed silica composites with different surface functional groups was calculated, and the results are shown in Figure 5c. Evidently, the crosslinking density of the PDMS-treated silica composite is slightly higher than that of the untreated silica composite. The crosslinking density and $\mathrm{T}_{\mathrm{g}}$ of the epoxy/fumed silica composites increased because of the PDMS treatment-induced interfacial interactions between the fumed silica particles and the epoxy matrix.

Flexural tests were performed to confirm the mechanical properties of the epoxy composite material. The interaction between the nanofiller particles and the matrix was confirmed by applying a continuous force to the structure. Figure $6 \mathrm{~b}, \mathrm{c}$ show that the flexural strength and modulus increase with increase in the filler content for untreated fumed silica composite. In the PDMS-treated fumed silica/epoxy composite, the flexural strength is maximum at $2 \mathrm{wt} . \%$ and then decreases; however, the modulus continues to increase. The attraction between the polymer and the filler gave rise to the observed flexural strength of the composite, leading to an increase in its maximum bending strength. In particular, the PDMS-treated composite showed maximum strength at a low silica content owing to the strong interaction of the fumed silica particles with the polymer matrix. The flexural modulus of a material is defined as the stress that resists deformation in the material. The modulus of elasticity of the PDMS surface-treated fumed silica/epoxy composite is slightly higher than that of the untreated fumed silica/epoxy composite. The obtained flexural modulus indicates weak interaction between the filler and the polymer matrix, contrary to the case of flexural strength (Figure 6a). 
(a)
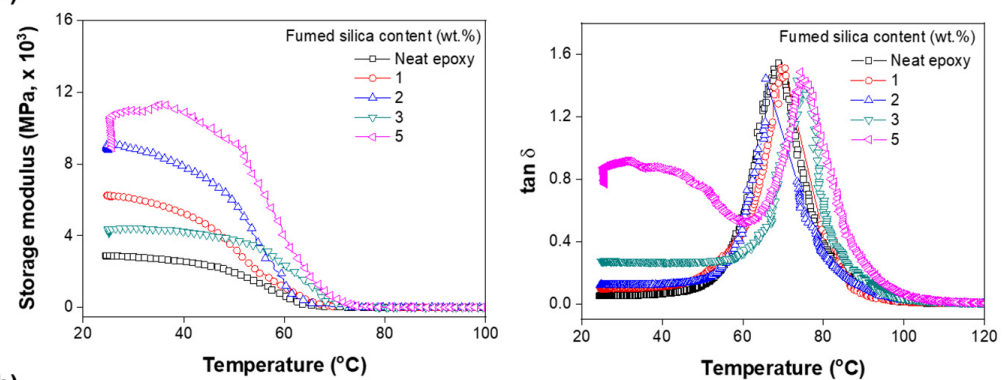

(b)
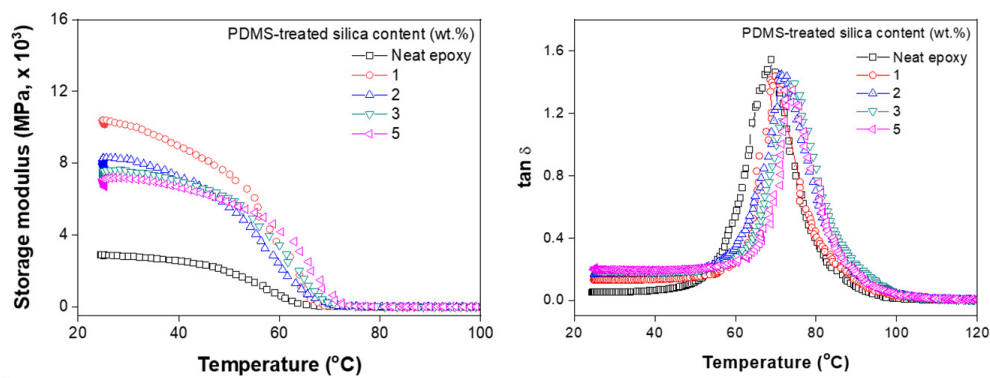

(c)

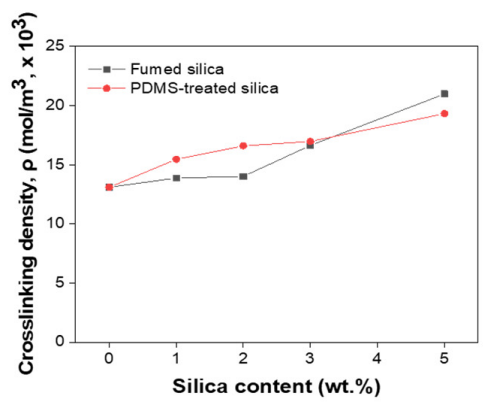

Figure 5. Variations in the storage modulus and tan $\delta$ values of the epoxy composites as functions of (a) fumed silica and (b) PDMS-treated fumed silica contents. (c) Crosslinking densities of epoxy/fumed silica and epoxy/PDMS-treated silica composites with silica content.

(a)

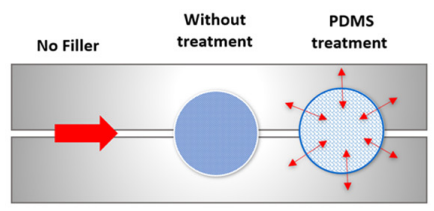

$<$ Flexural strength >

(b)

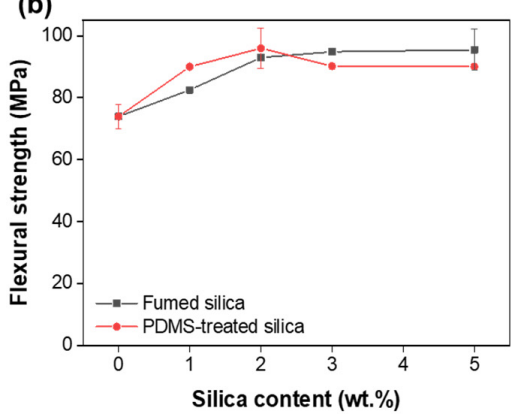

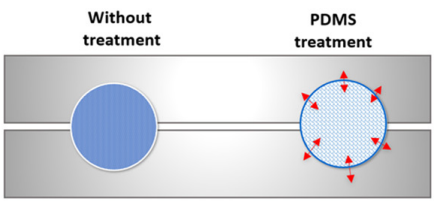

$<$ Modulus >

(c)

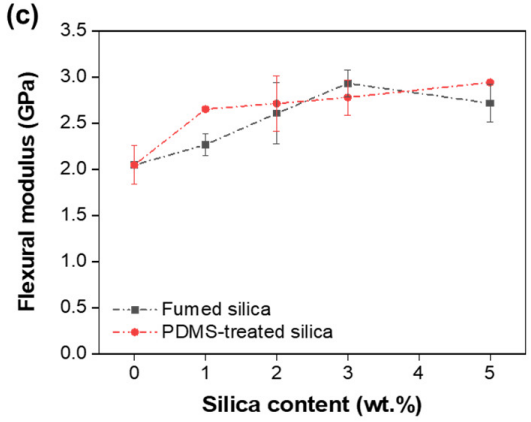

Figure 6. (a) Illustration of mechanical properties. Variations in the (b) flexural strength and (c) flexural modulus of the epoxy/fumed silica composites as functions of silica content. 


\section{Conclusions}

The dispersibility of fumed silica particles in a polymer matrix was confirmed by measuring the viscosity of a mixture of fumed silica and epoxy resin with different surface properties. Depending on the surface treatment of fumed silica, shear thinning behavior and Newtonian behavior was observed in the composite. In particular, the initial viscosity of the PDMS-treated silica mixture increased with increase in the silica content. In the curing reaction of the mixture, the maximum temperature at the exothermic peak decreased as the content of the fumed silica filler was increased. These results show that the fumed silica filler has a catalytic effect on the epoxy curing reaction. Additionally, the $\mathrm{Td}_{5}$, char content, and IPDT of the composites were analyzed. The addition of silica nanoparticles improved the thermal stability of the composite and slowed down the pyrolysis process. The crosslinking density and $\mathrm{T}_{\mathrm{g}}$ of the epoxy/fumed silica composites increased because of the interfacial interaction between the PDMS-treated fumed silica particles and the epoxy matrix. The flexural strength of the epoxy nanocomposite was very high even at a low silica content, because of the strong interactions between the PDMS-treated fillers and the epoxy matrix. These strong interfacial interactions originate from the attractive forces between the polymer and the filler. Therefore, surface-treated fumed silica is a promising filler material for industrial applications.

Supplementary Materials: The following are available online at https:/ /www.mdpi.com/article/10 .3390/polym13162691/s1, Figure S1: Specimens images of (a) Epoxy/fumed silica composites (b) Epoxy/PDMS-treated composites, Figure S2: FESEM images of (a) hydrophilic fumed silica and (b) hydrophobic PDMS-treated fumed silica nanoparticles, Figure S3: FTIR spectra of fumed silica and PDMS-treated fumed silica nanoparticles, Figure S4: DSC results of (a) epoxy/fumed silica composites and (b) epoxy/PDMS-treated fumed silica composites, Figure S5: TGA results of (a) Epoxy/fumed silica composites (b) Epoxy/PDMS-treated composites. (c) Schematic representation of S1, S2, and S3 for A* and K*. (d) TGA curves of fumed silica nanoparticles, Figure S6: (a) DMA results of the epoxy/fumed silica composites. (b) DMA results of the epoxy/PDMS-treated fumed silica composites. (c) Storage modulus of the epoxy/fumed silica composites. (d) Storage modulus of epoxy/PDMS-treated fumed silica composites.

Author Contributions: Conceptualization, H.-J.K. and K.-M.K.; methodology, H.K.; software, K.-M.K.; validation, K.-M.K.; formal analysis, H.K.; investigation, K.-M.K.; resources, K.-M.K.; data curation, H.-J.K. and K.-M.K.; writing—original draft preparation, K.-M.K.; writing—review and editing, H.-J.K.; visualization, H.K.; supervision, H.-J.K.; project administration, H.-J.K. All authors have read and agreed to the published version of the manuscript.

Funding: This work was financially supported by the Korea Evaluation Institute of Industrial Technology (KEIT) funded by the Ministry of Trade, Industry \& Energy (MOTIE, Korea, 20010881).

Institutional Review Board Statement: Not applicable.

Informed Consent Statement: Not applicable.

Data Availability Statement: Data is contained within the article.

Acknowledgments: We would like to thank Anton Paar Korea for their free support of rheological test and to MTM Corporation for their helping in the maintenance of the UTM Z010.

Conflicts of Interest: The authors declare no conflict of interest.

\section{References}

1. Balguri, P.K.; Samuel, D.G.H.; Thumu, U. A review on mechanical properties of epoxy nanocomposites. Mater. Today Proc. 2021, 44, 346-355. [CrossRef]

2. Jancar, J.; Douglas, J.F.; Starr, F.W.; Kumar, S.K.; Cassagnau, P.; Lesser, A.J.; Sternstein, S.S.; Buehler, M.J. Current issues in research on structure-property relationships in polymer nanocomposites. Polymer 2010, 51, 3321-3343. [CrossRef]

3. Gomez-Romero, P. Hybrid organic-inorganic materials-In search of synergic activity. Adv. Mater. 2001, 13, 163-174. [CrossRef]

4. Sanchez, C.; Julián, B.; Belleville, P.; Popall, M. Applications of hybrid organic-inorganic nanocomposites. J. Mater. Chem. 2005, 15, 3559-3592. [CrossRef] 
5. Mammeri, F.; Le Bourhis, E.; Rozes, L.; Sanchez, C. Mechanical properties of hybrid organic-inorganic materials. J. Mater. Chem. 2005, 15, 3787-3811. [CrossRef]

6. Woldemariam, M.H.; Belingardi, G.; Koricho, E.G.; Reda, D.T. Effects of nanomaterials and particles on mechanical properties and fracture toughness of composite materials: A short review. AIMS Mater. Sci. 2019, 6, 1191-1212. [CrossRef]

7. Spange, S. Silica surface modification by cationic polymerization and carbenium intermediates. Prog. Polym. Sci. 2000, 25, 781-849. [CrossRef]

8. Sindorf, D.W.; Maciel, G.E. Solid-State NMR Studies of the Reactions of Silica Surfaces with Polyfunctional Chloromethylsilanes and Ethoxymethylsilanes. J. Am. Chem. Soc. 1983, 105, 3767-3776. [CrossRef]

9. Guan, M.; Hao, L.; Chen, L.; Gao, F.; Qiu, S.; Zhou, H.; Chen, H.; Zhou, X. Facile Mechanical-Induced Functionalization of Hexagonal Boron Nitride and Its Application as Vehicles for Antibacterial Essential Oil. ACS Sustain. Chem. Eng. 2020, 8, 15120-15133. [CrossRef]

10. Tarrío-Saavedra, J.; López-Beceiro, J.; Naya, S.; Artiaga, R. Effect of silica content on thermal stability of fumed silica/epoxy composites. Polym. Degrad. Stab. 2008, 93, 2133-2137. [CrossRef]

11. Guo, Q.; Zhu, P.; Li, G.; Huang, L.; Zhang, Y.; Lu, D.D.; Sun, R.; Wong, C. One-pot synthesis of bimodal silica nanospheres and their effects on the rheological and thermal-mechanical properties of silica-epoxy composites. RSC Adv. 2015, 5, 50073-50081. [CrossRef]

12. Ochi, M.; Matsumura, T. Thermomechanical properties and phase structure of epoxy/silica nano-hybrid materials constructed from a linear silicone oligomer. J. Polym. Sci. Part B Polym. Phys. 2005, 43, 1631-1639. [CrossRef]

13. Battistella, M.; Cascione, M.; Fiedler, B.; Wichmann, M.H.G.; Quaresimin, M.; Schulte, K. Fracture behaviour of fumed silica/epoxy nanocomposites. Compos. Part A Appl. Sci. Manuf. 2008, 39, 1851-1858. [CrossRef]

14. Shirono, H.; Amano, Y.; Kawaguchi, M.; Kato, T. Characteristics of alkyltrimethoxysilane-treated fumed silicas and rheological behavior of fumed silica suspensions in an epoxy resin. J. Colloid Interface Sci. 2001, 239, 555-562. [CrossRef]

15. El-Fattah, M.A.; El Saeed, A.M.; El-Ghazawy, R.A. Chemical interaction of different sized fumed silica with epoxy via ultrasonication for improved coating. Prog. Org. Coat. 2019, 129, 1-9. [CrossRef]

16. Ghosh, S.; Goswami, S.K.; Mathias, L.J. Surface modification of nano-silica with amides and imides for use in polyester nanocomposites. J. Mater. Chem. A 2013, 1, 6073-6080. [CrossRef]

17. Wang, Y.; Zhou, C.; Zhang, Q.; Huang, Z. Synthesis of Fumed Silica Treated with Organosilane and Its Effect on Epoxy Resin. Polym. Plast. Technol. Eng. 2013, 52, 145-148. [CrossRef]

18. Choi, J.R.; Park, S.J. A study on thermal conductivity and fracture toughness of alumina nanofibers and powders-filled epoxy matrix composites. Polym. Korea 2013, 37, 47-51. [CrossRef]

19. Chen, Z.K.; Yang, G.; Yang, J.P.; Fu, S.Y.; Ye, L.; Huang, Y.G. Simultaneously increasing cryogenic strength, ductility and impact resistance of epoxy resins modified by n-butyl glycidyl ether. Polymer 2009, 50, 1316-1323. [CrossRef]

20. Preghenella, M.; Pegoretti, A.; Migliaresi, C. Thermo-mechanical characterization of fumed silica-epoxy nanocomposites. Polymer 2005, 46, 12065-12072. [CrossRef]

21. Sasidharan, S.; Anand, A. Epoxy-Based Hybrid Structural Composites with Nanofillers: A Review. Ind. Eng. Chem. Res. 2020, 59, 12617-12631. [CrossRef]

22. Li, Z.; Okamoto, K.; Ohki, Y.; Tanaka, T. Effects of nano-filler addition on partial discharge resistance and dielectric breakdown strength of Micro-Al2O3/epoxy composite. IEEE Trans. Dielectr. Electr. Insul. 2010, 17, 653-661. [CrossRef]

23. Patil, P.N.; Roilo, D.; Brusa, R.S.; Miotello, A.; Checchetto, R. Influence of nano-level molecular packing on the gas transport properties in amine-modified epoxy resins. Polymer 2015, 58, 130-138. [CrossRef]

24. Wang, Z.; Yang, X.; Wang, Q.; Hahn, H.T.; Lee, S.G.; Lee, K.H.; Guo, Z. Epoxy resin nanocomposites reinforced with ionized liquid stabilized carbon nanotubes. Int. J. Smart Nano Mater. 2011, 2, 176-193. [CrossRef]

25. Mai, V.D.; Lee, D.-I.; Park, J.H.; Lee, D.S. Rheological properties and thermal conductivity of epoxy resins filled with a mixture of alumina and boron nitride. Polymers 2019, 11, 597. [CrossRef] [PubMed]

26. Jiang, W.; Jin, F.L.; Park, S.J. Thermo-mechanical behaviors of epoxy resins reinforced with nano-Al $2 \mathrm{O} 3$ particles. J. Ind. Eng. Chem. 2012, 18, 594-596. [CrossRef]

27. Jin, F.L.; Park, S.J. Thermal properties of epoxy resin/filler hybrid composites. Polym. Degrad. Stab. 2012, 97, 2148-2153. [CrossRef]

28. Omrani, A.; Simon, L.C.; Rostami, A.A. The effects of alumina nanoparticle on the properties of an epoxy resin system. Mater. Chem. Phys. 2009, 114, 145-150. [CrossRef]

29. Huang, G.C.; Lee, J.K. Isothermal cure characterization of fumed silica/epoxy nanocomposites: The glass transition temperature and conversion. Compos. Part A Appl. Sci. Manuf. 2010, 41, 473-479. [CrossRef]

30. Chae, G.S.; Park, H.W.; Kwon, K.; Shin, S. Comparative study of the impact wedge-peel performance of epoxy structural adhesives modified with functionalized silica nanoparticles. Polymers 2021, 13, 469. [CrossRef]

31. Dittanet, P.; Pearson, R.A. Effect of silica nanoparticle size on toughening mechanisms of filled epoxy. Polymer 2012, 53, 1890-1905. [CrossRef]

32. Chan, C.M.; Wu, J.; Li, J.X.; Cheung, Y.K. Polypropylene/calcium carbonate nanocomposites. Polymer 2002, 43, $2981-2992$. [CrossRef]

33. Verma, V.; Sayyed, A.H.M.; Sharma, C.; Shukla, D.K. Tensile and fracture properties of epoxy alumina composite: Role of particle size and morphology. J. Polym. Res. 2020, 27, 388. [CrossRef] 
34. Kumar, R.; Mohanty, S.; Nayak, S.K. Study on epoxy resin-based thermal adhesive filled with hybrid expanded graphite and graphene nanoplatelet. SN Appl. Sci. 2019, 1, 1-13. [CrossRef]

35. Mariappan, T.; Wilkie, C.A. Flame retardant epoxy resin for electrical and electronic applications. Fire Mater. 2014, 38, 588-598. [CrossRef]

36. Chiang, C.L.; Hsu, S.W. Synthesis, characterization and thermal properties of novel epoxy/expandable graphite composites. Polym. Int. 2010, 59, 119-126. [CrossRef]

37. Zhang, X.; Li, S.; Wang, Z.; Sun, G.; Hu, P. Thermal stability of flexible polyurethane foams containing modified layered double hydroxides and zinc borate. Int. J. Polym. Anal. Charact. 2020, 25, 499-516. [CrossRef]

38. Liu, S.H.; Shen, M.Y.; Kuan, C.F.; Kuan, H.C.; Ke, C.Y.; Chiang, C.L. Improving thermal stability of polyurethane through the addition of hyperbranched polysiloxane. Polymers 2019, 11, 697. [CrossRef] [PubMed]

39. Liu, Y.L.; Wei, W.L.; Hsu, K.Y.; Ho, W.H. Thermal stability of epoxy-silica hybrid materials by thermogravimetric analysis. Thermochim. Acta 2004, 412, 139-147. [CrossRef]

40. Marunaka, R.; Kawaguchi, M. Rheological behavior of hydrophobic fumed silica suspensions in aromatic dispersion media. $J$. Dispers. Sci. Technol. 2017, 38, 223-228. [CrossRef]

41. Kang, S.; Hong, S.I.; Choe, C.R.; Park, M.; Rim, S.; Kim, J. Preparation and characterization of epoxy composites filled with functionalized nanosilica particles obtained via sol-gel process. Polymer 2001, 42, 879-887. [CrossRef]

42. Keller, A.; Chong, H.M.; Taylor, A.C.; Dransfeld, C.; Masania, K. Core-shell rubber nanoparticle reinforcement and processing of high toughness fast-curing epoxy composites. Compos. Sci. Technol. 2017, 147, 78-88. [CrossRef]

43. Gu, H.; Ma, C.; Gu, J.; Guo, J.; Yan, X.; Huang, J.; Zhang, Q.; Guo, Z. An overview of multifunctional epoxy nanocomposites. J. Mater. Chem. C 2016, 4, 5890-5906. [CrossRef]

44. Yu, J.; Huang, X.; Wu, C.; Wu, X.; Wang, G.; Jiang, P. Interfacial modification of boron nitride nanoplatelets for epoxy composites with improved thermal properties. Polymer 2012, 53, 471-480. [CrossRef] 